\title{
Structure and Properties of Nano- and Microcomposite Coating Based on $\mathrm{Ti}-\mathrm{Si}-\mathrm{N} / \mathrm{WC}-\mathrm{Co}-\mathrm{Cr}$
}

\author{
A.D. Pogrebnjak ${ }^{a, b, c, *}$, A.P. ShPaK ${ }^{a}$, V.M. BeresneV $^{d}$, M.V. IL'YAShenko $^{b}$, \\ F.F. Komarov ${ }^{e}$, A.P. Shypylenko ${ }^{a, b}$, M.V. KAVerin $^{a, b}$, P.V. Zukovski ${ }^{f}$, \\ Y.A. Kunitskyi ${ }^{a}$, D.A. Kolesnikov ${ }^{g}$, O.V. Kolisnichenko ${ }^{h}$ And N.A. Makhmudov ${ }^{i}$ \\ ${ }^{a}$ G.V. Kurdyumov Institute for Metal Physics, NAS Ukraine, Kiev, Ukraine \\ ${ }^{b}$ Sumy State University, Sumy Institute for Surface Modification, Sumy, Ukraine \\ ${ }^{c}$ Sumy State University, 40007, Sumy, Ukraine \\ ${ }^{d}$ Science Center for Physics and Technology, Kharkov, Ukraine \\ ${ }^{e}$ Belarus State University, Minsk, Belarus \\ ${ }^{f}$ Lublin Technical University, Lublin, Poland \\ ${ }^{g}$ Belgorod State University, Belgorod, Russia \\ ${ }^{h}$ O.E. Paton Welding Institute, NAS of Ukraine, Kiev, Ukraine \\ ${ }^{i}$ Samarkand State University, Samarkand, Uzbekistan
}

\begin{abstract}
Using the two technologies: plasma-detonation and vacuum-arc deposition, we fabricated two types of coatings: $\mathrm{Ti}-\mathrm{Si}-\mathrm{N} / \mathrm{WC}-\mathrm{Co}-\mathrm{Cr} /$ steel and $\mathrm{Ti}-\mathrm{Si}-\mathrm{N} /$ steel. We found that the top coating of $\mathrm{Ti}-\mathrm{Si}-\mathrm{N}$ was nanostructured one with 12 to $15 \mathrm{~nm}$ grain sizes and $H=40$ to $38 \mathrm{GPa}$ hardness. A thick coating which was deposited using the pulsed plasma jet, demonstrated 11 to $15.3 \mathrm{GPa}$ hardness, an elastic modulus $(E)$ changing within 176 to $240 \mathrm{GPa}$, and tungsten carbide grain dimensions varying from 150 to $350 \mathrm{~nm}$ to several microns. An X-ray diffraction analysis shows that the coating has the following phase composition: TiN, (Ti,Si) N solid solution, $\mathrm{WC}, \mathrm{W}_{2} \mathrm{C}$ tungsten carbides. An element analysis was performed using energy dispersive spectroscopy (microanalysis) and scanning electron microscopy, as well as the Rutherford backscattering of ${ }^{4} \mathrm{He}^{+}$ion and the Auger electron spectroscopy. Surface morphology and structure were analyzed using scanning electron microscopy and scanning tunnel microscopy. Tests friction and resistance (cylinder-plane) demonstrated essential resistance to abrasive wear and corrosion in the solution. The decrease of grain dimensions $\leq 10 \mathrm{~nm}$ occurring in the top Ti-Si-N coating layer increased the sample hardness to $42 \pm 2.7 \mathrm{GPa}$ under $\mathrm{Ti}_{72}-\mathrm{Si}_{8}-\mathrm{N}_{20}$ at.\% concentration.
\end{abstract}

PACS: 61.46.-w, 62.20.Qp, 62.25.-g

\section{Introduction}

Nanocomposite materials as a class of nanomaterials are characterized by heterogeneous structure, which was formed by practically non-interacting phases with the grain dimensions 5 to $35 \mathrm{~nm}[1]$. As a rule, the components of such structure are amorphous matrix and inclusions of nanocrystalline phases. These amorphous components agree in the best way with the nanocrystalline surfaces providing good adhesion and essentially increasing hardness. Small grain dimensions of the second phase in combination with good strength of intergrain boundaries provide high mechanical properties of such composition materials.

Today nanomaterials are divided into three classes according to their hardness values: hard nanocomposites of $H \geq 20$ to $40 \mathrm{GPa}$ hardness, superhard of 40 to $80 \mathrm{GPa}$,

* corresponding author; e-mail: alexp@i.ua and ultrahard of $\geq 80 \mathrm{GPa}[2]$. In addition to the protecting functions, chemical and machine building industries need restoration of initial tool dimensions for the tools, which already function in industry. For these purposes, tools covered with thick coatings, the physical and mechanical properties of which are higher than those of basic material. Usually, the alloys (powders) $\mathrm{Ni}-\mathrm{Cr}-\mathrm{Mo}$, the hard alloys $\mathrm{WC}-\mathrm{Co}-\mathrm{Cr}$ and $\mathrm{Cr}_{3} \mathrm{C}_{2}-\mathrm{Ni}$, and oxide ceramics $\mathrm{Al}_{2} \mathrm{O}_{3}, \mathrm{Al}_{2} \mathrm{O}_{3}-\mathrm{Cr}_{2} \mathrm{O}_{3}$ are used for such coatings [3].

In such way, combination of two layers, for example a thick layer of $\mathrm{WC}-\mathrm{Co}-\mathrm{Cr}$ hard alloy of $100 \mu \mathrm{m}$, which was formed using cumulative or detonation deposition, and $\mathrm{Ti}-\mathrm{Si}-\mathrm{N}$ thin upper layer (units of a micron) with enhanced physical-mechanical characteristics, which was formed by subsequent condensation, was able to provide higher protecting functions and restore worn surface regions.

The aim of this work is manufacturing of $\mathrm{Ti}-\mathrm{Si}-\mathrm{N}-$, $\mathrm{Ti}-\mathrm{Si}-\mathrm{N} / \mathrm{WC}-\mathrm{Co}-\mathrm{Cr}$-based coatings and investigation of their physical and mechanical properties. 


\section{Experimental details}

The polished samples of Steel 45 ( $0.45 \% \mathrm{C}$, Fe the rest) of $4 \mathrm{~mm}$ and $20 \mathrm{~mm}$ diameters were coated using a vacuum-arc source with high-frequency discharge. The Ti alloyed sintered cathode containing 5 to $10 \mathrm{wt} \%$ of Si was deposited using the Bulat $3 \mathrm{~T}$-device functioning under $5 \times 10^{-5} \mathrm{~Pa}$ vacuum and $100 \mathrm{~A}$ cathode current. The sputtering was carried out using two regimes: the standard vacuum-arc method, and high-frequency (HF)-regime. A bias potential was applied to the substrate from the HF generator, which produced impulses of convergent oscillations with $\leq 1 \mathrm{MHz}$ frequency, the duration of impulse was $60 \mu \mathrm{s}$, their repetition frequency - about $10 \mathrm{kHz}$. Due to HF diode effect the value of negative auto bias potential occurring in the substrate amounted to 2 to $3 \mathrm{kV}$ at the beginning of impulse (after start of discharger operation). The coatings of 2 to $3.5 \mu \mathrm{m}$ thickness were deposited on the steel substrates of 20 and $30 \mathrm{~mm}$ diameters, and 3 to $5 \mathrm{~mm}$ thickness without additional substrate heating. Molecular nitrogen was employed as a reactive gas. The first series of rounded steel $3(0.3 \mathrm{wt} \% \mathrm{C})$ samples of $20 \mathrm{~mm}$ diameter and 4 to $5 \mathrm{~mm}$ thickness were deposited using the cumulative-detonation device CDS- 1 of the following parameters: $65 \mathrm{~mm}$ distance to a nozzle cut, $14 \mathrm{~mm} / \mathrm{s}$ displacement velocity, 5 runs, $12 \mathrm{~Hz}$ pulse repetition frequency (for $\mathrm{WC}-\mathrm{Co}-\mathrm{Cr}$ ). After the deposition, the 160 to $320 \mu \mathrm{m}$ thick coating was melted by plasma jet (without powder) using eroding $\mathrm{W}$ electrode. A melted layer thickness was 45 to $60 \mu \mathrm{m}$. Then, the $\mathrm{Ti}-\mathrm{Si}-\mathrm{N}$ thin coating of about $3 \mu \mathrm{m}$ was deposited over the thick one using the same device Bulat $3 \mathrm{~T}$ (the method was described above).

For element analysis, we applied the following methods: Rutherford backscattering of ${ }^{4} \mathrm{He}^{+}$of $1.76 \mathrm{MeV}$ energy (RBS), scanning electron microscopy (SEM) with energy dispersive spectroscopy (EDS) (REMMA-103M, Selmi, Ukraine), X-ray diffraction (DRON-3 and Advantage 8, USA).

Hardness and elastic modulus were measured using the nanoindentation device - Nanoindenter II, MTS System Corporation, Oak Ridge TN (USA) with the Berkovich pyramid. Elastic modulus was determined using the "load-unload" curves, according to the OliverPharr method [1, 3]. Scanning tunneling microscope $(\mathrm{STM})$ of $1 \mathrm{~nm}$ resolution was used to study the thin layer surface morphology.

\section{Results and discussion}

The cumulative-detonation device functioned under the conditions of detonation burning combustion gaseous mixtures. The cumulative-detonation device functioned under conditions of detonation burning of combustion gaseous mixtures. The device (Fig. 1) was constructed of the following parts. The detonation chamber (1) serves to burn gaseous combustion mixtures. Cumulative detonation chamber (2) works at any concentrations of combus- tion mixtures and allows formation of high-velocity gas jet with excess nitrogen or carbon. The cylindrical nozzle (3) serves for heating and acceleration of powders. It was manufactured of copper tubes and could be adopted to any cross-section configuration. Its output diameter was 10 to $30 \mathrm{~mm}$. The component (4) feeds and stops gaseous mixtures. To initiate detonation, we applied a sparking plug (5). A device has input for a mixture of gaseous components (6).

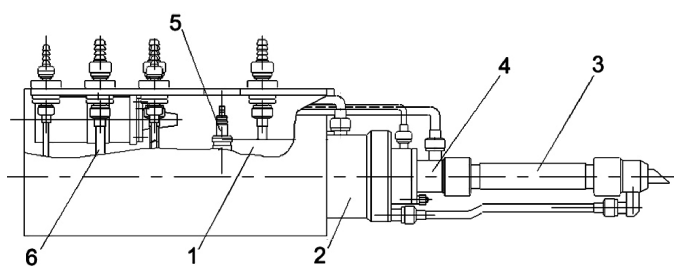

Fig. 1. The cumulative-detonation device. 1 - detonation chamber, 2 - cumulative detonation chamber, 3 - cylindrical nozzle, 4 - gas feeding component, 5 - sparking plug, 6 - device input.

Basic difference between the cumulative-detonation and detonation devices is that the former utilized combined energies of detonation combustion products from several specially designed chambers. Cumulative energy allows high-velocity gas to flow with several shock waves providing efficient interactions with powder material. In this way, energy of combustion mixtures is rationally used. The rate and temperature of combustion products depend only on combustion conditions in every chamber. Nozzles function not less than $1000 \mathrm{~h}$. High burning frequency of 15 to $30 \mathrm{~Hz}$ is able to provide quasi-continuous coating deposition.

To increase the potential of technological system, the generator, which allows reaching up to $100 \mathrm{~kW}$ impulse of HF discharge, was constructed on the basis of pulsed generator with impact contouring.

An advantage of such generators is that their operation weakly depended on changes of loading impedance, which was principally important for functioning under pulsed mode and under pulsed loading.

Discharge starts at aluminum coils, then it displaces to copper electrodes with good heat conductivity. The discharge unit has special holes for air cooling of plates. Application of such construction provides high voltages and generator operation stability.

Spark resistance of discharge units was calculated using the perfect Tamppler formula [4]:

$$
R=2.5 \times 10^{-8} \mathrm{f} / \mathrm{c},
$$

where $c$ is the capacity value, which was discharged with $f$ discharge frequency.

Operating parameters for the tested generator with $f_{0}=1 \mathrm{MHz}, \rho=-10 \Omega, C=T_{p f}, L=5 \mu \mathrm{G}$, $U_{0}=10 \mathrm{kV}, t_{\mathrm{ipl}}=30 \mu \mathrm{s}$, stored capacitor energy was $E_{0}=2.5 \mathrm{~J}$, pulsed power $P_{\text {pulse }}=8.3 \mathrm{~kW}$. The calculation demonstrated that under periodical discharge 
$t_{\text {pulse }}=1.5 \mu \mathrm{s}, P_{\text {pulse }}=1.6 \mathrm{MW}$, repetition frequency $f=3.0 \mathrm{kHz}, t_{\text {rep }}=330 \mu \mathrm{s}$, an average power $P=$ $7.5 \mathrm{~kW}$, discharge current $I=10^{3}$ A.

HF generator, which switches plasma-producing antennae, operates in two modes: (1) with open input (ohmic circuit-zero distance between the antenna and ground) and (2) with closed input - the antenna is separated from the ground by capacity.

Charged plasma particles in the electric HF field of the antenna $E$ reached the following velocity:

$$
V=\frac{e E}{m w},
$$

where $e$ is the particle charge, $m$ is the particle mass, $w$ is the cyclic generator frequency.

Then, the particle range in the field $E$ and under $w$ frequency will be

$$
Z_{\max }=\frac{e E}{m w^{2}} .
$$

Selecting $E$ and $f$ such that an electron range was several centimeters $(\mathrm{cm})$, ion remaining practically non-mobile, and the antenna HF voltage started to be detected by plasma.

Under the closed input mode, the antenna was negatively charged, and under the open input mode, electrons left the zone of antenna.

Without the external magnetic field this zone is

$$
\delta \approx \frac{C}{2 \pi \times 10^{4} \sqrt{n_{\mathrm{e}}}},
$$

where $c$ is the light velocity $[\mathrm{m} / \mathrm{s}], n_{\mathrm{e}}$ is the plasma density $\left[\mathrm{cm}^{-3}\right]$.

In such way, working with the decreasing voltage (Fig. 2) during every impulse, one can join two main technological operations of coating deposition (clearing and deposition), which earlier were performed separately using the devices for vacuum-arc deposition.

It allows to choose better conditions for coating deposition and to save time. Depositing $\mathrm{Al}_{2} \mathrm{O}_{3}$ and $\mathrm{TiN}$ coatings, it was demonstrated that changing $\mathrm{HF}$ voltage potential applied to the substrate, one could affect coating phase composition [1-4].

Figure 3 represents the image of nano-microcomposite surface for the combined $\mathrm{Ti}-\mathrm{Si}-\mathrm{N} / \mathrm{WC}-\mathrm{Co}-\mathrm{Cr}$ coating.

A thin coating is formed using the vacuum-arc source and follows the coating surface relief formed by plasma-detonation. Its average roughness varies from 14 to $22 \mu \mathrm{m}$ (after melting and coating deposition using the vacuum-arc source). An image of X-ray energy dispersion spectrum is presented below. It indicates the following element concentrations in the thin coating: $N \approx 7.0$ to 7.52 vol. $\%$; $\mathrm{Si} \approx 0.7$ vol. $\%$; $\mathrm{Ti} \approx 76.70$ to 81 vol. $\%$. For the thick coating we found $\mathrm{Fe} \approx 0.7$ vol. $\%$, and traces of $\mathrm{Ni}$ and $\mathrm{Cr}$.

Figure 4 presents the RBS data for the thick WC-Co-Cr coating without $\mathrm{Ti}-\mathrm{Si}-\mathrm{N}$ thin one, and the results for the combined coating are presented below.

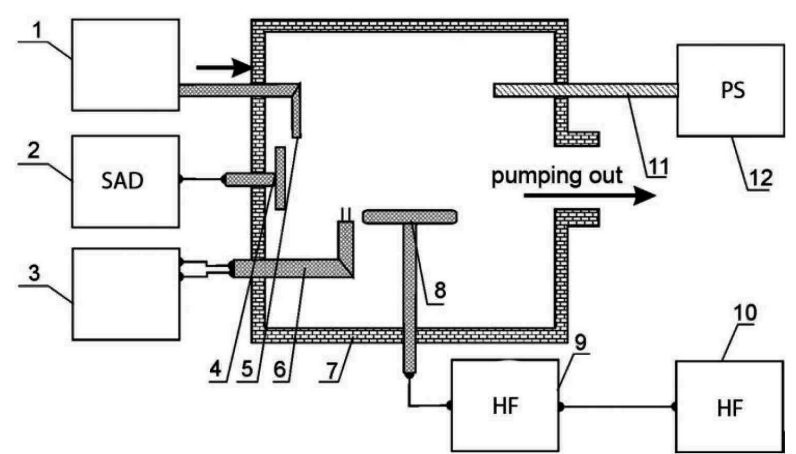

Fig. 2. A scheme of the technological system for coating synthesis operating on the basis of vacuum-arc discharge: 1 - the gas-feeding device, 2 - the sources for arc-discharge feeding, 3 - the measuring probe, 4 - the cathode, 5 - the gas line for gas-feeding, 6 - the double movable probe, 7 - the vacuum chamber, 8 - the substrate, 9 - the device to match the HF-generator, 10 - the HF-generator, 11 - the quartz tube for dissociation of working gas molecules, 12 - the power source.

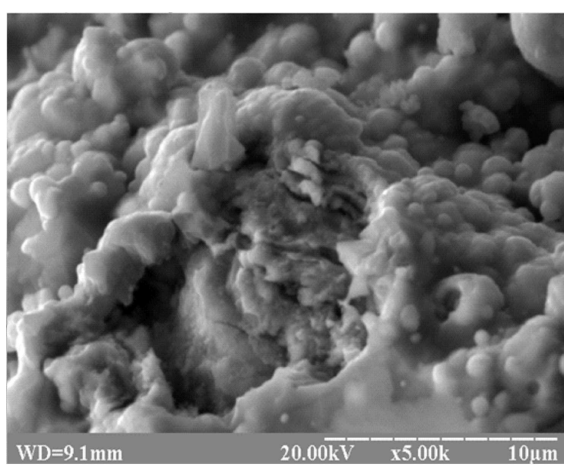

Fig. 3. Images of surface regions for the nano-microcomposite combined coating $\mathrm{Ti}-\mathrm{Si}-\mathrm{N}$ / $\mathrm{WC}-\mathrm{Co}-\mathrm{Cr}$.

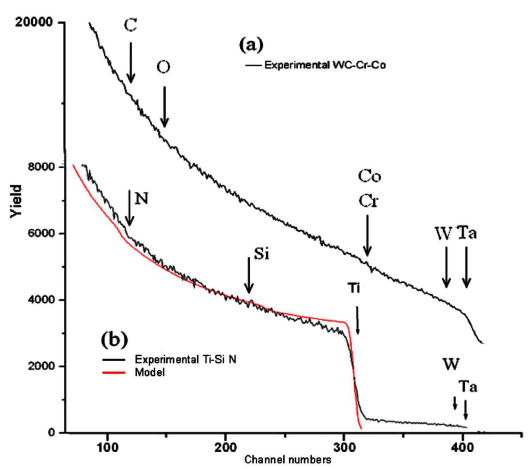

Fig. 4. (a) Energy spectra of the RBS for the thick coating WC-Co-Cr. (b) Energy spectra of the RBS for the top thin coating $\mathrm{Ti}-\mathrm{Si}-\mathrm{N} / \mathrm{WC}-\mathrm{Co}-\mathrm{Cr}$. 
The element distribution, which was calculated according to standard program [5], indicated $\mathrm{N}=30$ at.\%; $\mathrm{Si} \approx 5$ to 6 at. $\% ; \mathrm{Ti} \approx 63$ to 64 at.\%. The spectrum of thick coating did not allow us to evaluate the element concentration due to high surface roughness of the coating formed by the plasma-detonation method.

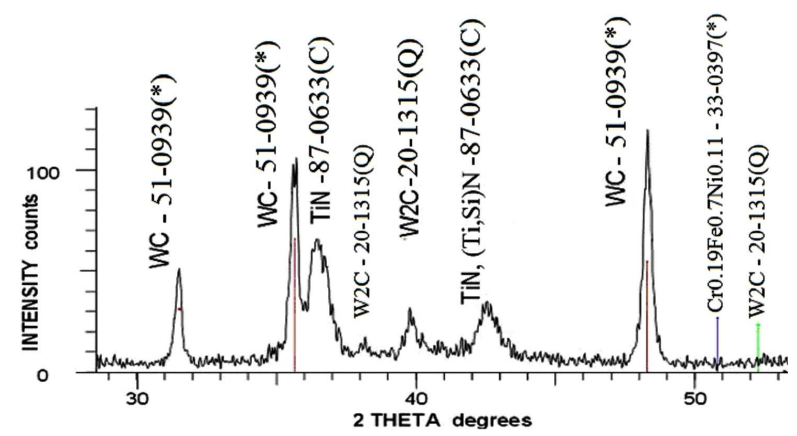

Fig. 5. Diffraction patterns fragments obtained for the surface region of the nano-microcomposite combined coating $\mathrm{Ti}-\mathrm{Si}-\mathrm{N} / \mathrm{WC}-\mathrm{Co}-\mathrm{Cr} /$ steel substrate.

The X-ray analysis of the combined nanocomposite coating is shown in Fig. 5. It indicates the following phases: (Ti,Si)N; TiN — for the thin coating, and WC; $\mathrm{W}_{2} \mathrm{C}$ - for the thick one.

Special samples were prepared for hardness measurements. Their surfaces were grinded and then polished. After grinding, thickness of $\mathrm{WC}-\mathrm{Co}-\mathrm{Cr}$ thick coating decreased to $80-90 \mu \mathrm{m}$. A thin Ti-Si-N film of about $3 \mu \mathrm{m}$ was deposited on the grinded surface. As a result, we found that the hardness of different regions essentially varied within $30 \pm 4 \mathrm{GPa}$ to $38 \pm 6 \mathrm{GPa}$. Probably, it is related to non-uniformity of plasma-detonation coating surface, whose hardness varied up from 11.5 to $15.3 \mathrm{GPa}$. These hardness values remained after deposition of the $\mathrm{Ti}-\mathrm{Si}-\mathrm{N}$ thin coating. Elastic modulus also features non-ordinary behavior.

Hardness of the thin coating, which was deposited to a polished steel Steel $45(0.45 \% \mathrm{C})$ surface had the maximum value of $45 \mathrm{GPa}$, and its average value $H_{\mathrm{av}}$ was $45 \mathrm{GPa}$. Variation of hardness values was lower than that found in a combined coating.

Figure 6 shows the dependences of loading-unloading for various indentation depths.

The dependences and calculations, which were performed according to the Oliver-Pharr technique [1, 4], show that the hardness of $\mathrm{Ti}-\mathrm{Si}-\mathrm{N}$ coatings deposited on thick WC-Co-Cr was 37.0 $14.0 \mathrm{GPa}$ under $E=483 \mathrm{GPa}$.

In the coating, basic phases are $\mathrm{Cr}_{3} \mathrm{Ni}_{2}$ for the bottom thick coating and $(\mathrm{Ti}, \mathrm{Si}) \mathrm{N}$ and TiN for the thin top coating. Diffraction patterns were taken under cobalt emission. Additionally, we found phases of pure $\mathrm{Cr}$ and low concentration of titanium oxide $\left(\mathrm{Ti}_{9} \mathrm{O}_{17}\right)$ at interface boundary between the thin-thick coatings. The peaks of Ti-Si-N and TiN coincided because of low Si content. $(\mathrm{Ti}, \mathrm{Si}) \mathrm{N}$ is a solid solution based on TiN ( $\mathrm{Si}$ penetra-

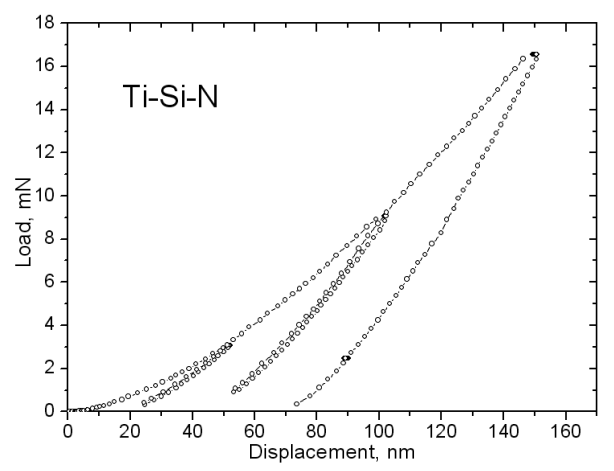

Fig. 6. Loading-unloading curves for the $\mathrm{Ti}-\mathrm{Si}-\mathrm{N} /$ $\mathrm{WC}-\mathrm{Co}-\mathrm{Cr}$ coating under various Berkovich indentation depths.

tion). The phases are well distinguished at 72 to $73^{\circ}$ angles [6-8].

The results of wear resistance tests, which were performed according to the scheme "cylinder-plane", demonstrated the lowest friction wear for the $\mathrm{Ti}-\mathrm{Si}-\mathrm{N} /$ $\mathrm{WC}-\mathrm{Co}-\mathrm{Cr}$ system and the highest friction wear for the substrate [9-11].

Adhesion between the thin $\mathrm{Ti}-\mathrm{Si}-\mathrm{N}$ coating and the thick $\mathrm{WC}-\mathrm{Co}-\mathrm{Cr}$ one was 1.75 times larger than that between $\mathrm{Ti}-\mathrm{Si}-\mathrm{N}$ and $\mathrm{WC}-\mathrm{Co}-\mathrm{Cr}$. In addition, the adhesion between the thick $\mathrm{WC}-\mathrm{Co}-\mathrm{Cr}$ coating and steel (substrate) was 7.2 times larger and more than 12.5 times larger than between the thick $\mathrm{WC}-\mathrm{Co}-\mathrm{Cr}$ coating and steel (substrate) respectively. The maximum adhesion value of about $2920 \mathrm{~N} / \mathrm{m}^{2}$ was found in the case of $\mathrm{Ti}-\mathrm{Si}-\mathrm{N} \rightarrow \mathrm{WC}-\mathrm{Co}-\mathrm{Cr}[12]$.

\section{Conclusion}

The thick $(>100 \mu \mathrm{m})$ nanocomposite coatings of $\mathrm{Ti}-\mathrm{Si}-\mathrm{N} / \mathrm{WC}-\mathrm{Co}$ compositions were formed and investigated.

In the first series of samples, thin coatings contained (Ti,Si)N and TiN phases. Grain sizes were about $25 \mathrm{~nm}$. Hardness was about 30-38 GPa.

In the second series of samples, in thin coating the grain dimensions were smaller - about $15 \mathrm{~nm}$. The hardness reached 42 to $45 \mathrm{GPa}$. The phase composition was the same - $(\mathrm{Ti}, \mathrm{Si}) \mathrm{N}$ and TiN. Si and N concentrations changed from 10 at. $\%$ to 5 at. $\%$ for Si and from 30 at.\% to 20 at.\% for $\mathrm{N}$.

Wear resistance increased essentially, which was demonstrated by cylinder-to-sample surface friction. Corrosion resistance and other mechanical characteristics also increased.

\section{Acknowledgments}

The work was supported by the projects ISTCs K-1198 and NAS of Ukraine "Nanosystems, Nanocoatings, Nanomaterials". 
The authors acknowledge Drs. S.B. Kislitsyn, Yu.Zh. Tuleushev from the Institute for Nuclear Physics, NNC, Almaty, for their help in RBS analysis and corrosion tests.

\section{References}

[1] A.D. Pogrebnjak, A.P. Shpak, N.A. Azarenkov, V.M. Beresnev, Usp. Phys. 170, 35 (2009).

[2] R.F. Zhang, A.S. Argon, S. Veprek, Phys. Rev B 79, 24542 (2009).

[3] S. Veprek, M.G.J. Veprek-Heijman, P. Karvankova, J. Prochazka, Thin Solid Films 476, 1 (2005).

[4] A.D. Pogrebnjak, M.M. Danilionok, V.V. Uglov, N.K. Erdybaeva, G.V. Kirik, S.N. Dub, V.S. Rusakov, A.P. Shypylenko, P.V. Zukovski, Y.Zh. Tuleushev, Vacuum 83, S235 (2009).

[5] A. Cavaleiro, J.Th.M. De Hosson, Nanostructured Hard Coating, Kluwer Academic/Plenum Pub., New York 2005.
[6] J. Musil, P. Dohnal, P. Zeman, J. Vac. Sci. Technol. 23, 1568 (2005).

[7] A.D. Pogrebnyak, O.V. Sobol, V.M. Beresnev, P.V. Turbin, S.N. Dub, Tech. Phys. Lett. 35, 925 (2009).

[8] V.M. Beresnev, O.V. Sobol, A.D. Pogrebnjak, P.V. Turbin, S.V. Litovchenko, Tech. Phys. 80, 117 (2010).

[9] A.D. Pogrebnyak, M.M. Danilenok, A.A. Drobyshevskaya, V.M. Beresnev, Russ. Phys. J. 52, 1317 (2009).

[10] A.V. Khomenko, N.V. Prodan, Carbon 48, 1234 (2010).

[11] A.V. Khomenko, N.V. Prodan, J. Phys. Chem. C 114, 19958 (2010)

[12] J. Musil, Nanostructured Hard Coatings, Kluwer Academic/Plenum Pub., New York 2007. 